Research Article

\title{
Disturbance Evolution Behavior of Loess Soil under Triaxial Compression
}

\author{
Yali Xu' and Panpan Guo iD ${ }^{2,3}$ \\ ${ }^{1}$ School of Urban Construction and Transportation, Hefei University, Hefei 230601, China \\ ${ }^{2}$ Research Center of Coastal and Urban Geotechnical Engineering, Zhejiang University, Hangzhou 310058, China \\ ${ }^{3}$ School of Civil Engineering, Hefei University of Technology, Hefei 230009, China
}

Correspondence should be addressed to Panpan Guo; pp_guo@zju.edu.cn

Received 25 December 2019; Revised 16 March 2020; Accepted 19 March 2020; Published 15 April 2020

Academic Editor: Liborio Cavaleri

Copyright (C) 2020 Yali Xu and Panpan Guo. This is an open access article distributed under the Creative Commons Attribution License, which permits unrestricted use, distribution, and reproduction in any medium, provided the original work is properly cited.

\begin{abstract}
This paper presents an investigation into the evolution law of the structural effects of Xi'an loess soil, based on the disturbed state concept. First, a series of consolidated and drained triaxial compression tests were performed on undisturbed and remoulded loess samples prepared at five different moisture contents and tested at four different confining pressures. Second, two disturbance functions with different parameters were proposed to quantify mathematically the structural effects of loess. Finally, the proposed disturbance functions were validated against documented test results by other researchers. The results indicated that the singleparameter disturbance function, with the deformation modulus as its parameter, provides convenience for application but takes no account of the respective contributions of deviatoric stress and mean stress to the disturbance evolution behavior of loess. The double-parameter disturbance function, with the shear and bulk moduli as its parameters, is capable of distinguishing these respective contributions and reflects well the disturbance evolution behavior of loess under various moisture contents and confining pressures. The effects of moisture content and confining pressure on the parameters of the disturbance functions were found to be unsteady. The proposed disturbance functions lay the foundation for establishing a constitutive model for loess accounting for the structural effect.
\end{abstract}

\section{Introduction}

Because of the unique formation and geological conditions, loess soil is characterized by containing a great amount of randomly distributed macropores, strong particle bonding, and acute water sensitivity [1-5]. Therefore, it is difficult to model the mechanical behavior of loess soil. In spite of this difficulty, an investigation into the disturbance evolution behavior of structural loess soil is of great significance because it affects the safety and stability of the infrastructures built in the loess area.

Many scholars have carried out different researches into structural soil and have achieved some results. Gao [6] studied the microstructure of loess and the structural theory of loess collapsible deformation by scanning electron microscopy (SEM). The results indicated that the collapsibility of loess was closely related to the type of microstructure. Chen [7] adopted the CT method to study the microstructure of unsaturated structural soil and developed an elastic-plastic model for structural soil. Fang et al. [8], taking into consideration the evolution of meso-structure, carried out CT tests on unsaturated loess soil. A constitutive model for unsaturated loess was established based on the testing results. On the basis of the theory of damage mechanics, the composite model, masonry model, and binary medium model for structural soil were proposed by Shen and his colleagues [9-11]. However, it is difficult to propose a universal parameter quantifying the microstructure feature of loess. The difficulty may be caused by the complex loess forming process and stress history and a variety of the factors affecting the structural behavior of loess. In addition, the application of the proposed disturbance functions is very 
limited because of the complexity of the function form and the inability to account for the strength increase phenomenon after strength softening.

According to the theory of soil mechanics as well as the results of compression tests, Xie and Qi [12] proposed a parameter $m_{p}$ to quantitatively describe soil structure. This parameter is called comprehensive structure potential. Since the proposal of the concept of comprehensive structural potential, many other concepts have been proposed by the students of Xie. These concepts are based on the structural parameters of principal stress difference, comprehensive structural potential of strain [13], void ratio, principal stress difference, test cone, stress ratio, and structural index [14]. These studies on the basis of soil mechanics take no account of the soil particle bonding and combination characteristics and thus fail to capture the variation of loess structural behavior with evolution of an external load. An alternative method for modelling the structural behavior of loess is based on solid mechanics. This method has the advantages of effectively describing the loess microstructure change and disturbance during loading and of avoiding measuring parameters quantifying the loess microstructure features. Therefore, this method has been adopted in this study for modelling the structural behavior of Xi'an loess soil.

The disturbed state theory was proposed by Desai in 1974, who also established an elastic-plastic model for clay [15-19]. Xu [20-22] investigated the mechanical properties of structural loess in Xi'an and proposed a one-dimensional disturbance function. The evolution law of the one-dimensional disturbance function was analyzed, and a disturbance constitutive model for structural loess was also developed. Then, Shao and Chu [23] proposed the volumetric strain disturbance factor $\left(D_{v}\right)$ and the deviatoric strain disturbance factor $\left(D_{s}\right)$. Chu and Shao [24] carried out an experimental research on the $\mathrm{Q}_{3}$ loess in Longdong and proposed the volumetric strain disturbance factor $D_{p}$ and the shear strain disturbance factor $D_{q}$. The methods of establishing disturbance function discussed above are mainly based on mathematical derivation, and many assumptions have to be made. In these methods, many of the established disturbance functions are defined by void ratio or stress, which is incapable of reflecting the actual failure process of granular soil subjected to the combined disturbance of shear and volumetric strains. Because of this, further validation of these disturbance functions is needed by a good deal of experimental data.

Loess is a typical special type of soil and distributed widely in the Loess Plateau region of China. The honeycomb structure of loess soil accompanied with a large amount of micropores has not weakened the characteristics of high shear strength of loess soil [25-29]. Its structural characteristics of incomplete consolidation and water sensitivity are closely related to the collapsibility [30-34]. Under the effects of external load and water, loess soil exhibits crushing, rolling, and sliding, which causes change in loess particle distribution, number, shape, size, and arrangement. By performing a series of dynamic triaxial compression tests, $\mathrm{Wu}$ et al. [35] investigated the influence of structural parameters on the dynamic stress-strain behavior of loess soil collected from Ningxia, Shanxi, and Gansu. It was found that the probability entropy, porosity, fractal dimension, and equivalent diameter can be regarded as the structural parameters of loess soils, and with increasing the confining pressure and moisture content, the initial structural parameter was decreased. Zhang et al. [36] evaluated experimentally the influence of cyclic freeze and thaw on the physical and mechanical properties of compacted and limestabilized loess soil collected from Xining, China. The test results showed that the strength and modulus of loess soil were improved by 11 freeze-thaw cycles. Zhen et al. [37] studied the thermal conductivities of undisturbed and remolded Malan loess collected from the first terrace of the Yellow River and found that at a saturation degree and a dry density, the thermal conductivity of undisturbed loess was larger than that of remolded loess. To improve strength and deformation behavior of loess, stabilization of loess has been attempted using different materials such as novel reactive magnesia-bearing binders [38], lime and fly ash piles [39], and nanoclay [40]. However, the structural behavior of loess soil under triaxial compression has not been fully investigated because the applicability of the disturbance functions proposed in the literature is site-specific. In addition, the experimental data on undisturbed and remoulded loess which is requisite for validation of the proposed disturbance functions are rare. Consequently, experimental and modelling research work is still needed for further understanding of the disturbance evolution behavior of loess.

In this paper, the loess soil in Xi'an was taken as the research object. Based on the disturbance state theory, a single-parameter disturbance function $D_{1}$ with the deformation modulus as its parameter and a double-parameter disturbance function $D_{2}$ with the shear modulus and bulk modulus as its parameters were proposed. In addition, the parameters of the disturbance functions as well as the disturbance function evolution laws were analyzed with the help of the triaxial compression testing results.

\section{Experiment}

2.1. Soil Sample Preparation and Testing Apparatus. The undisturbed loess soil samples were taken from a construction site in the northern suburb of Xi'an, China. The depth at which the soil samples were taken was approximately $5.0 \mathrm{~m}$. The soil was yellow and in plastic state, categorized as typical loess soil $\mathrm{Q}_{3}$. The soil was classified as silty clay according to the Chinese Soil Classification System. Standard compaction tests were conducted to determine the maximum dry density and the optimum moisture content. The basic physical properties of the soil samples are shown in Table 1.

2.2. Testing Method. The soil was dug by hands in order to avoid disturbing and then cut into standard samples in a steel split mold. Soil specimens were manufactured to be an identical cylindrical shape of $80 \mathrm{~mm}$ in height and $39.1 \mathrm{~mm}$ in diameter. In order to investigate the disturbance evolution behavior of loess soil, conventional triaxial compression 
TABle 1: Physical and mechanical properties of undisturbed loess.

\begin{tabular}{lc}
\hline Property & Value \\
\hline Specific gravity & 2.71 \\
Natural moisture content $(\%)$ & 22 \\
Natural density $\left(\mathrm{g} / \mathrm{cm}^{3}\right)$ & 1.48 \\
Dry density $\left(\mathrm{g} / \mathrm{cm}^{3}\right)$ & 1.2 \\
Void ratio & 1.28 \\
Liquid limit $(\%)$ & 31.3 \\
Plastic limit $(\%)$ & 18.9 \\
Plasticity index & 12.4 \\
Saturated moisture content $(\%)$ & 46.5 \\
Optimum moisture content $(\%)$ & 27.2 \\
Maximum dry density $\left(\mathrm{g} / \mathrm{cm}^{3}\right)$ & 1.69 \\
Collapsibility coefficient & 0.017 \\
\hline
\end{tabular}

tests were performed on undisturbed and remoulded loess soil samples prepared at five different moisture contents (i.e., $8 \%, 16 \%, 22 \%, 28 \%$, and $46.5 \%)$. Triaxial compression tests were performed using a computer-controlled GDS (Global Digital System) triaxial testing system. This testing system, designed based on the Mohr-Coulomb strength theory, is capable of measuring the stress-strain relationship and shear failure strength of soil samples under different confining pressures. The confining pressure was applied to the soil sample in the axial chamber by the confining pressure loading system, and the axial stress was applied to the soil sample by the axial loading system which could control the strain rate while keeping the confining pressure constant. With increasing deviatoric stress, soil samples gradually reached the limit equilibrium state at which shear failure occurred.

The remoulded soil samples were compacted in five layers according to the standard procedure. The soil samples were saturated by the vacuum pumping method. All samples were completely saturated for 24 hours by adopting distilled water under vacuum conditions. The different moisture contents of soil samples were controlled by means of moisture migration and natural air drying. During tests, the adopted confining pressures applied on soil samples were of four magnitudes which were 50, 100, 200 , and $300 \mathrm{kPa}$.

\section{Disturbance Function and Evolution Law}

3.1. The Disturbed State Concept. The disturbed state concept (DSC) is a constitutive simulation method developed by Desai in 1974. The development of the DSC was based on the mechanical disturbance of materials $[15,16,21,22]$. According to this concept, a disturbance of material microstructure can inevitably trigger a change in its macroscopic mechanical properties. This corresponds to a selfadjustment transformation of the state of material microstructure from relatively intact (RI) to fully adjusted (FA). The disturbance process can be described through a disturbance function $D$ (also called disturbance factor) as depicted in Figure 1. The actual deformation of a material under stress is the superposition of the material deformations in two states, and therefore it can be expressed as

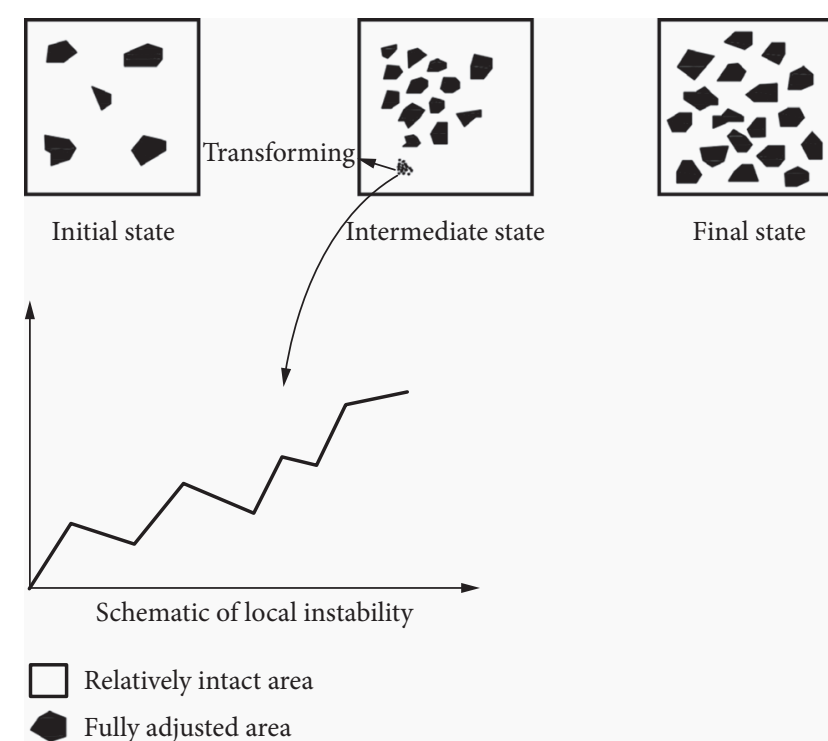

Figure 1: Schematic of the disturbed state concept.

$$
\varepsilon_{i j}=\left(1-D_{\varepsilon}\right) \varepsilon_{i j}^{i}+D_{\varepsilon} \varepsilon_{i j}^{c},
$$

where $\varepsilon_{i j}=$ strain tensor of the actual value, $D_{\varepsilon}=$ disturbance function, $\varepsilon_{i j}^{i}=$ strain tensor of the RI state, and $\varepsilon_{i j}^{c}=$ strain tensor of the FA state.

The conceptual incremental equation of the disturbed state can be obtained from the differential equation:

$$
d \varepsilon_{i j}=\left(1-D_{\varepsilon}\right) d \varepsilon_{i j}^{i}+D_{\varepsilon} d \varepsilon_{i j}^{c}+\left(\varepsilon_{i j}^{c}-\varepsilon_{i j}^{i}\right) d D_{\varepsilon} .
$$

\subsection{Single-Parameter Disturbance Function and Evolution Law}

3.2.1. Definition of Single-Parameter Disturbance Function. Based on the results of consolidated and drained triaxial compression tests on undisturbed and remoulded loess soil samples, the single-parameter disturbance function $D_{1}$ is proposed with the deformation modulus as its parameter:

$$
D_{1}=\frac{E_{i}-E}{E_{i}-E_{c}},
$$

where $E_{i}=$ modulus of the RI state, $E_{c}=$ secant modulus of the FA state, and $E=$ secant modulus between the RI state and the FA state, as shown in Figure 2.

\subsubsection{Evolution Law of Single-Parameter Disturbance}

Function. The evolution law of the single-parameter disturbance functions for undisturbed and remoulded loess soil samples under four different confining pressures and five different moisture contents is shown in Figure 3. It can be revealed from Figure 3 that the structural properties of the undisturbed loess soil samples prepared at relatively low moisture contents are more obvious. Due to its strong structural properties and the slight disturbance influence, the disturbance function is relatively small. With an increase in moisture content, the impact of water sensitivity on the 


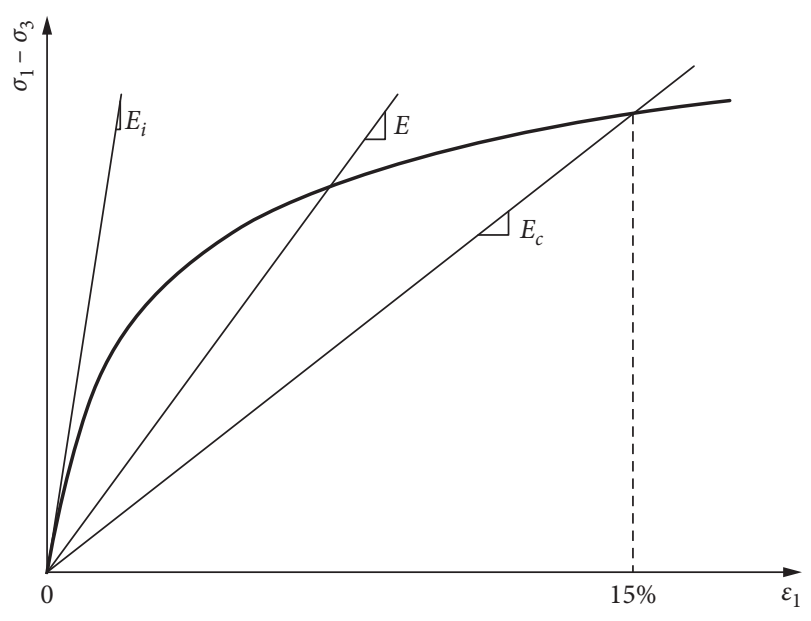

Figure 2: Determination of single-parameter disturbance function.

internal microstructure of loess soil becomes more significant. The loess structure composed of arrangements and connections is gradually enhanced due to the disturbance of water. Because of this, the disturbance factors gradually increase.

In addition, it can also be indicated from the curves of the remoulded loess soil samples in Figure 3 that the difference between the magnitudes of the single-parameter disturbance functions for undisturbed and remoulded loess soil samples is greater at an intermediate axial strain (i.e., $\left.2 \% \leq \varepsilon_{1} \leq 6 \%\right)$ than at extreme axial strains. Moreover, this difference is reduced with increasing the confining pressure from 50 to $300 \mathrm{kPa}$. At the confining pressures of 50 and $100 \mathrm{kPa}$, the effect of moisture content on the disturbance function for undisturbed soil samples is consistent with the effect of moisture content on the disturbance function for remoulded soil samples. However, this consistency no longer exists at the other two confining pressures. The reason for this may be that a higher confining pressure weakens the adverse effect of moisture content on the disturbance behavior of loess soil.

\subsection{Double-Parameter Disturbance Function and Evolution} Law. An analysis of the testing results indicates that the single-parameter disturbance function is unable to capture the contribution of the spherical stress and the deviatoric stress in different strains. In the meantime, the contribution made by deviatoric stress is different from the contribution made by spherical stress, due to the difference in the stress histories in the two cases. Therefore, a double-parameter disturbance function is proposed herein to better consider the disturbance influence. In other words, the relationship between the bulk modulus of the spherical stress and the disturbance function of the spherical stress, as well as the relationship between the disturbance function of the deviatoric stress and the shear modulus of the deviatoric stress are established.

Consequently, the disturbance function can be defined through the bulk modulus and the shear modulus as

$$
\begin{gathered}
D_{v}=\frac{K_{i}-K}{K_{i}-K_{c}}, \\
D_{s}=\frac{G_{i}-G}{G_{i}-G_{c}},
\end{gathered}
$$

where $K_{i}=$ bulk modulus of the RI state, $K_{c}=$ bulk modulus of the FA state, $G_{i}=$ shear modulus of the RI state, and $G_{c}=$ shear modulus of the FA state.

As for loess soil as a kind of nonlinear material, the modulus adopted frequently in application is secant modulus, as shown in Figures 4 and 5. These moduli vary in magnitude, depending on the measured equivalent strain. Thus, the disturbance functions $D_{v}$ and $D_{s}$ should also be a function of the equivalent strain. In this case, the disturbance functions based on volumetric strain and shear strain can be established with the help of the results of consolidated and drained triaxial compression tests on undisturbed and remoulded loess soil samples under different moisture contents and different confining pressures.

\subsubsection{Evolution Law of Disturbance Functions Based on} Volumetric Strain. The evolution law of the disturbance functions based on volumetric strain for undisturbed and remoulded soil samples under four confining pressures and five moisture contents is presented in Figure 6. From Figure 6 , it can be seen that both confining pressure and moisture content have an effect on the bulk modulus of loess soil. The disturbance function curves indicate that the effect of moisture content on the evolution law of the disturbance function for undisturbed soil samples is greater than that for remoulded soil samples. In the cases of lower confining pressures, the change of the evolution law of the disturbance function for undisturbed soil samples is smaller than that for remoulded soil samples. In the cases of higher confining pressures, the change of the evolution law of the disturbance function for undisturbed soil samples is larger than that for remoulded soil samples. For a specific moisture content, the effect of confining pressure on the evolution law of the disturbance function for undisturbed soil samples is greater than that for remoulded soil samples.

3.3.2. Evolution Law of Disturbance Functions Based on Shear Strain. The evolution law of the disturbance functions based on shear strain for undisturbed and remoulded loess soil samples is shown in Figure 7. It can be seen from Figures 6 and 7 that for both undisturbed and remoulded soil samples, the evolution law of the disturbance function based on volumetric strain and the evolution law of the disturbance function based on shear strain can be fitted as the following two equations. One is the disturbance function based on volumetric strain (i.e., $D_{v}$ ), and the other is the disturbance function based on shear strain (i.e., $D_{s}$ ):

$$
D_{v}=1-A_{v} \exp \left(-Z_{v} \varepsilon_{v}\right)
$$



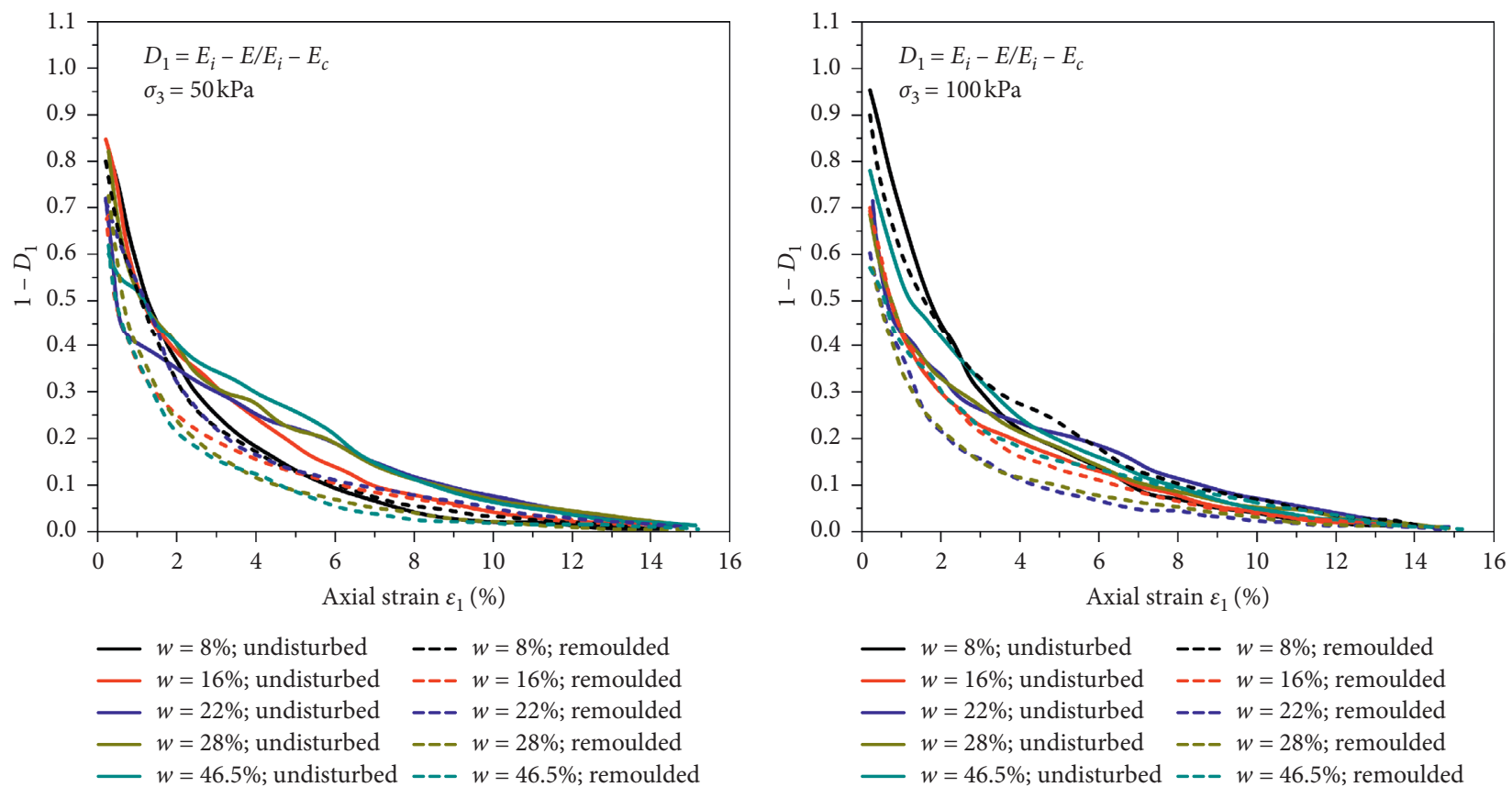

(a)
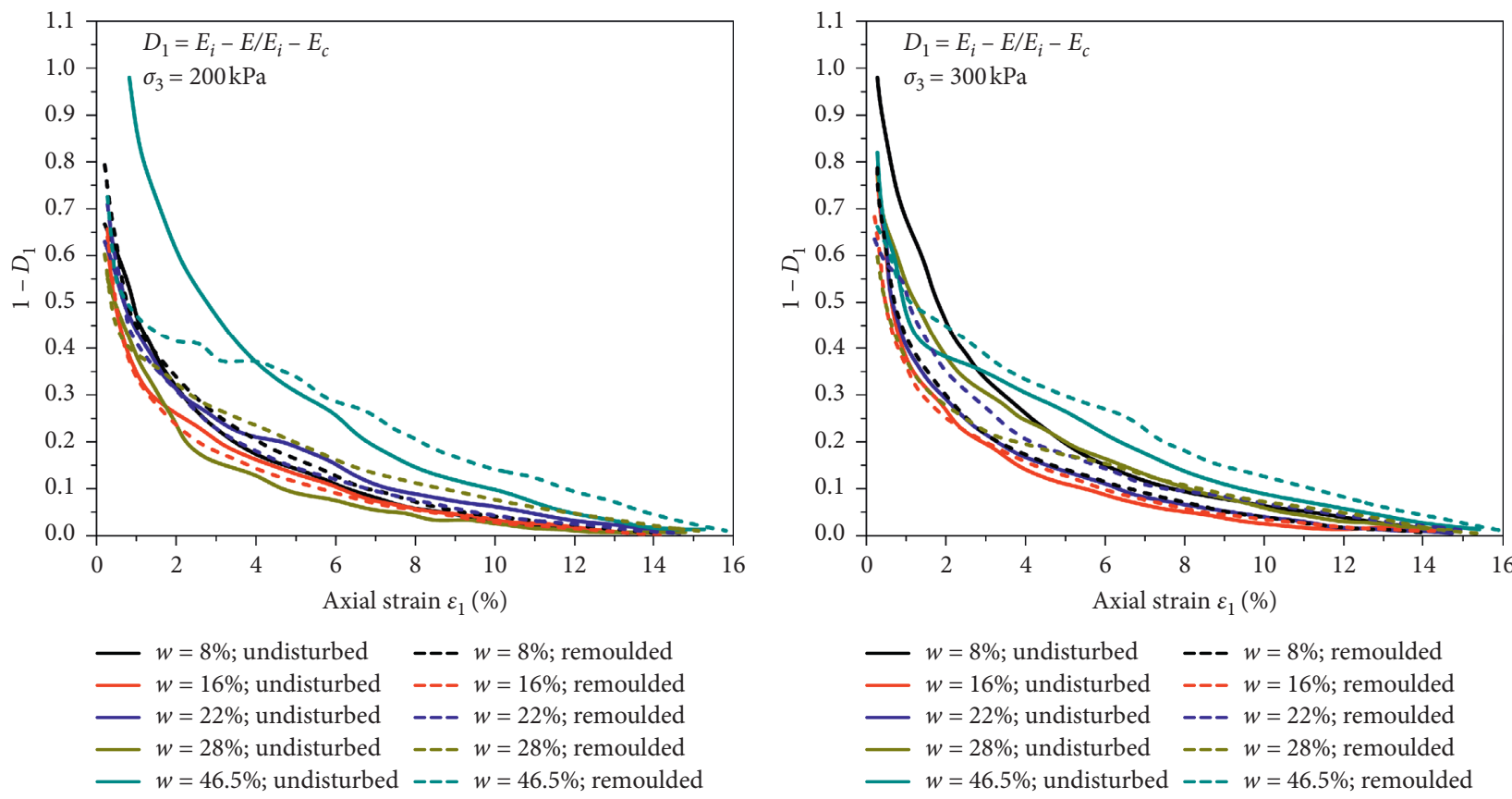

(c)

(d)

Figure 3: Evolution curves of single-parameter disturbance functions for undisturbed and remoulded soil samples. (a) $\sigma_{3}=50 \mathrm{kPa}$; (b) $\sigma_{3}=100 \mathrm{kPa} ;(\mathrm{c}) \sigma_{3}=200 \mathrm{kPa}$; (d) $\sigma_{3}=300 \mathrm{kPa}$.

$$
D_{s}=1-A_{s} \exp \left(-Z_{s} \varepsilon_{s}\right)
$$

where $A_{v}, Z_{v}, A_{s}$, and $Z_{s}$ are the parameters of the disturbance functions.

Equations (5) and (6) can be simplified as

$$
\begin{aligned}
& \ln \left(1-D_{v}\right)=\ln A_{v}-Z_{v} \varepsilon_{v}, \\
& \ln \left(1-D_{s}\right)=\ln A_{s}-Z_{s} \varepsilon_{s} .
\end{aligned}
$$

In this way, the relationship between $\ln \left(1-D_{v}\right)$ and $\varepsilon_{v}$ and the relationship between $\ln \left(1-D_{s}\right)$ and $\varepsilon_{s}$ can be established. By fitting the testing results with the least square method, the values of the parameters $A_{v}, Z_{v}, A_{s}$, and $Z_{s}$ in the disturbance functions for undisturbed and remoulded loess soil can be obtained. Disturbance Function Parameters. The effects of moisture 


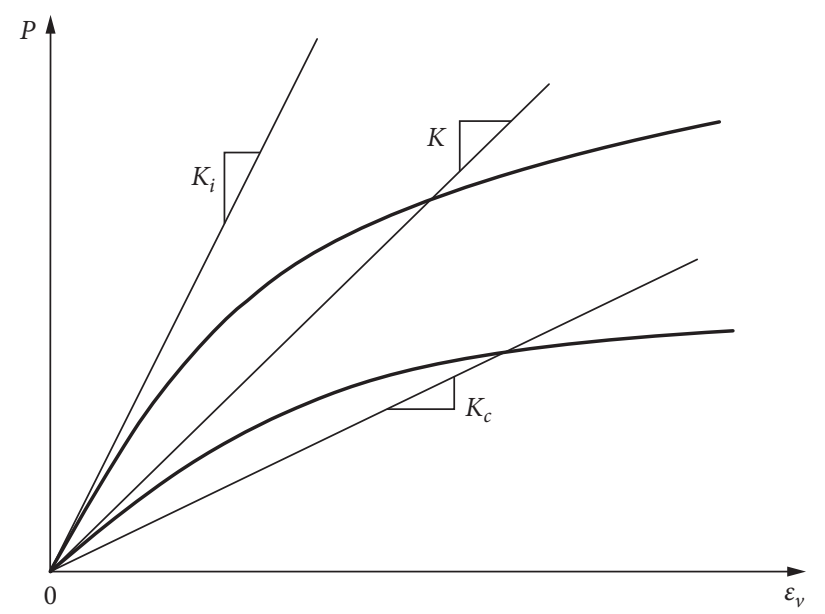

FIGURE 4: Determination of the disturbance function based on volumetric strain.

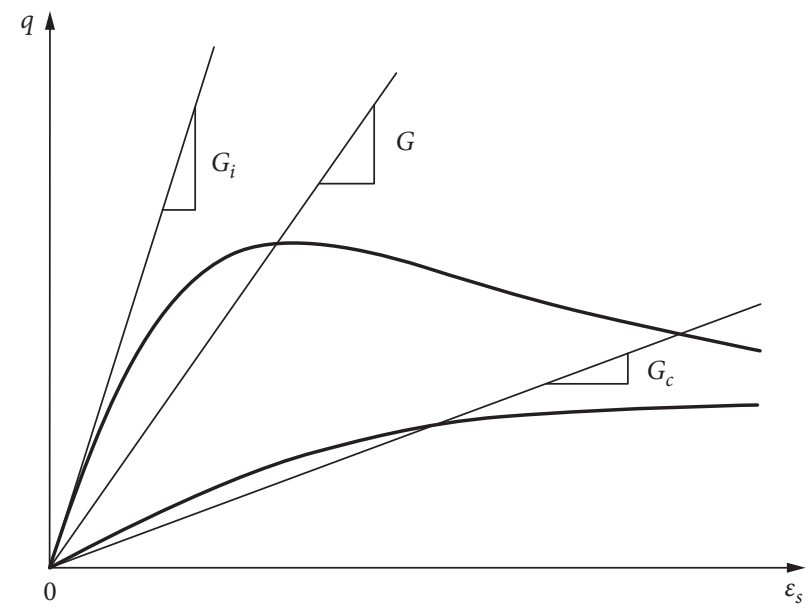

FIGURE 5: Determination of the disturbance function based on shear strain.

content and confining pressure on the parameters of the double-parameter disturbance functions for undisturbed and remoulded soil samples are presented in Figure 8. It can be seen from Figure 8 that compared with the single-parameter disturbance function, the effects of moisture content and confining pressure on the parameters of the doubleparameter disturbance functions are not conspicuous. Additional tests are, therefore, required for further investigation into the effects of moisture content and confining pressure on the parameters of the double-parameter disturbance functions.

\section{Validation of Disturbance Function}

The proposed single-parameter and double-parameter disturbance functions were validated against the experimental results by Chu and Shao [24] on the structural Q3 loess collected from Qingyang, China. Figure 9 presents a comparison of the variation of $\left(1-D_{1}\right)$ with axial strain from the experimental results by Chu and Shao [24] and the predicted results by the single-parameter disturbance function proposed in this study. The comparison was made for four different moisture contents (i.e., 10\%, 15\%, 20\%, and 25\%) and four different confining pressures (i.e., 100, 200, 300, and $400 \mathrm{kPa}$ ). From Figure 9, it can be indicated that the exponential single-parameter disturbance function captures well the experimentally observed disturbance evolution behavior of the undisturbed and remoulded loess soil in the Longdong area. In addition, a further comparison of the disturbance evolution laws at different moisture contents and confining pressures as shown in Figures 9(a)-9(d) reveals that the effects of moisture content and confining pressure on the parameters of the single-parameter disturbance function are different. This difference agrees with the results obtained in this study.

A comparison of the variation of $\left(1-D_{v}\right)$ with volumetric strain from the experimental results by Chu and Shao [24] and the predicted results by the proposed double-parameter disturbance function proposed based on bulk modulus is presented in Figure 10. It can be observed in Figure 10 that the proposed double-parameter disturbance function based on bulk modulus predicts accurately the experimental disturbance evolution behavior of the loess soil in Qingyang, China. Moreover, both the experimental and 

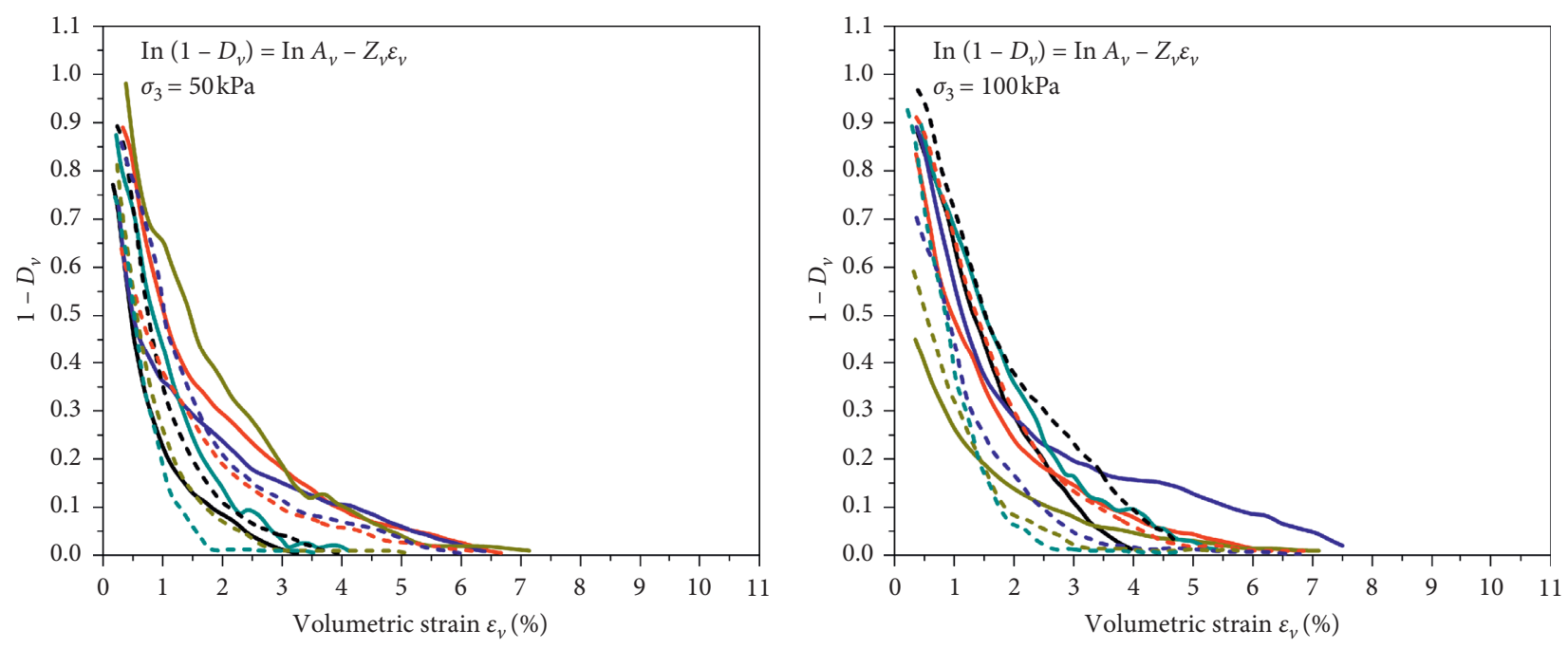

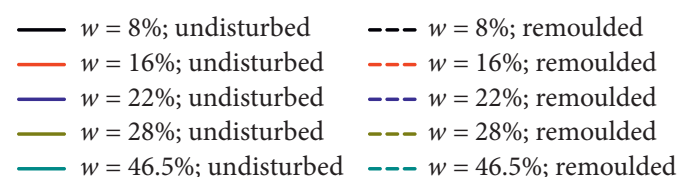

(a)
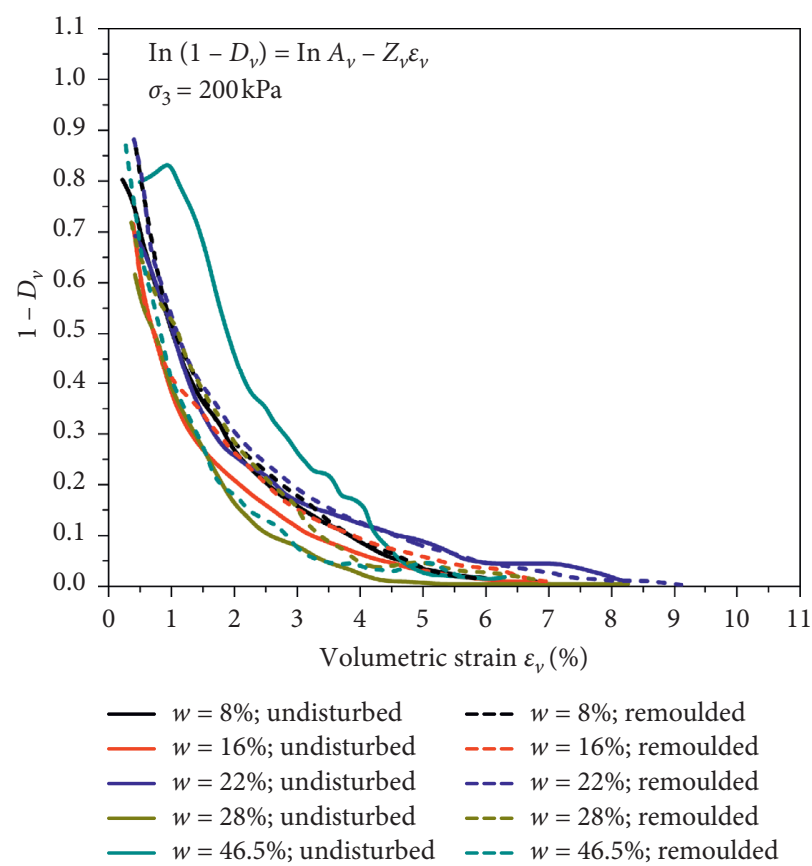

(c)

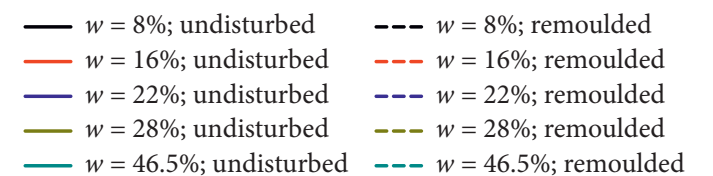

(b)
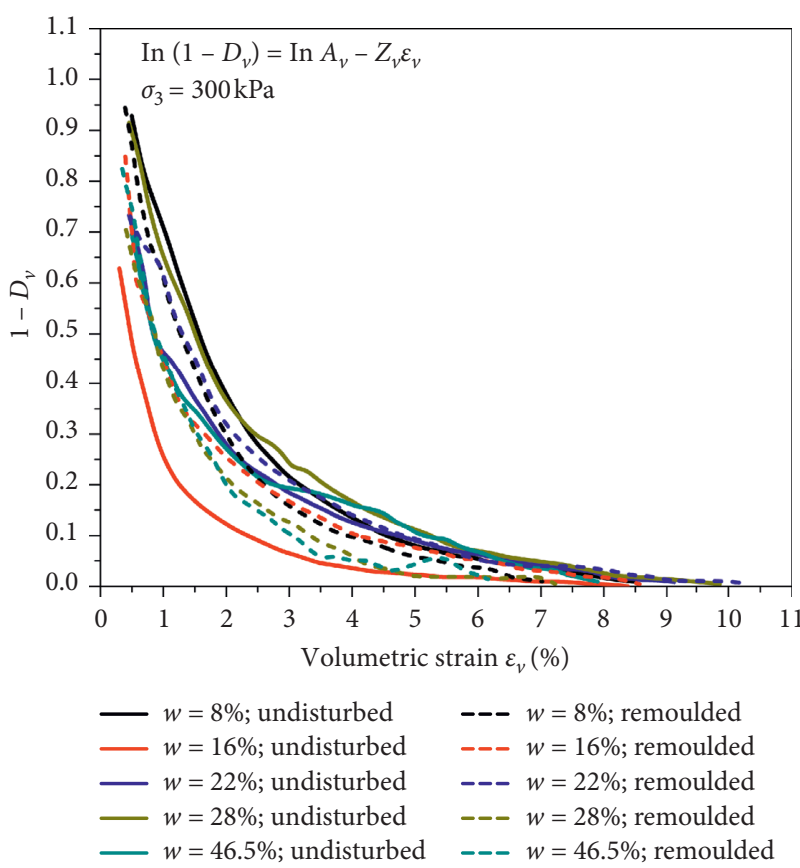

(d)

FIGURE 6: Evolution curves of disturbance functions based on volumetric strain for undisturbed and remoulded soil samples. (a) $\sigma_{3}=50 \mathrm{kPa}$; (b) $\sigma_{3}=100 \mathrm{kPa}$; (c) $\sigma_{3}=200 \mathrm{kPa}$; (d) $\sigma_{3}=300 \mathrm{kPa}$.

the predicted effects of moisture content and confining pressure on the disturbance evolution behavior of loess soil become more trivial with an increase in the magnitudes of moisture content and confining pressure. This consistency further validates the double-parameter disturbance function based on bulk modulus.

The experimentally observed and the predicted variations of $\left(1-D_{s}\right)$ with shear strain at different moisture contents and confining pressures are compared in Figure 11. The comparisons indicate that the effects of moisture content and confining pressure on the doubleparameter disturbance function based on shear strain (i.e., $D_{s}$ ) are smaller at lower magnitudes of moisture content and confining pressure than that at higher magnitudes of moisture content and confining pressure. With an increase in the magnitude of confining pressure, 

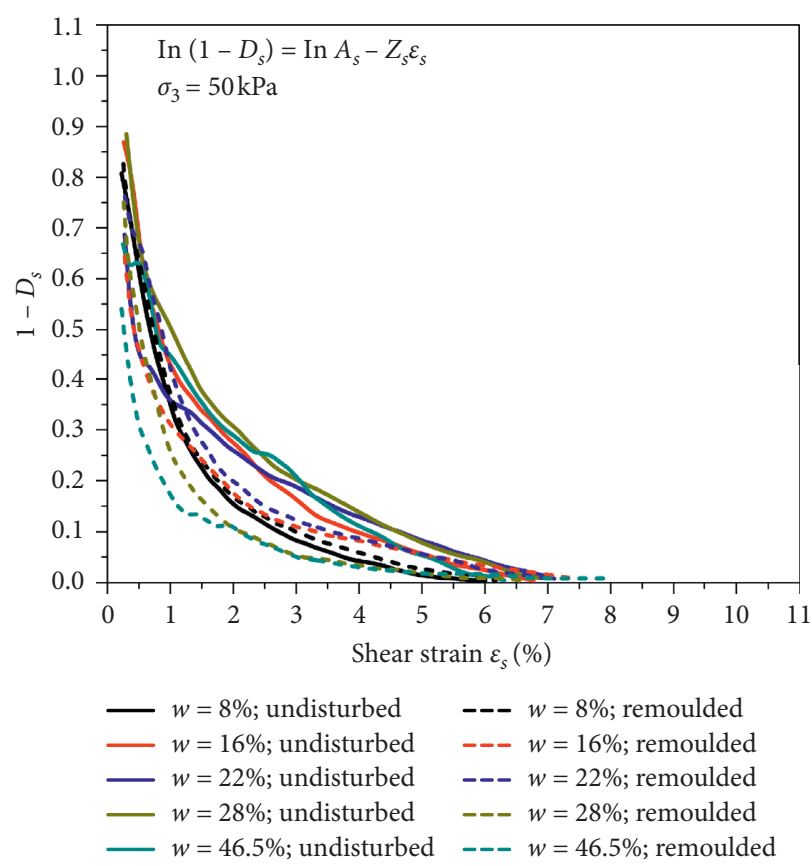

(a)

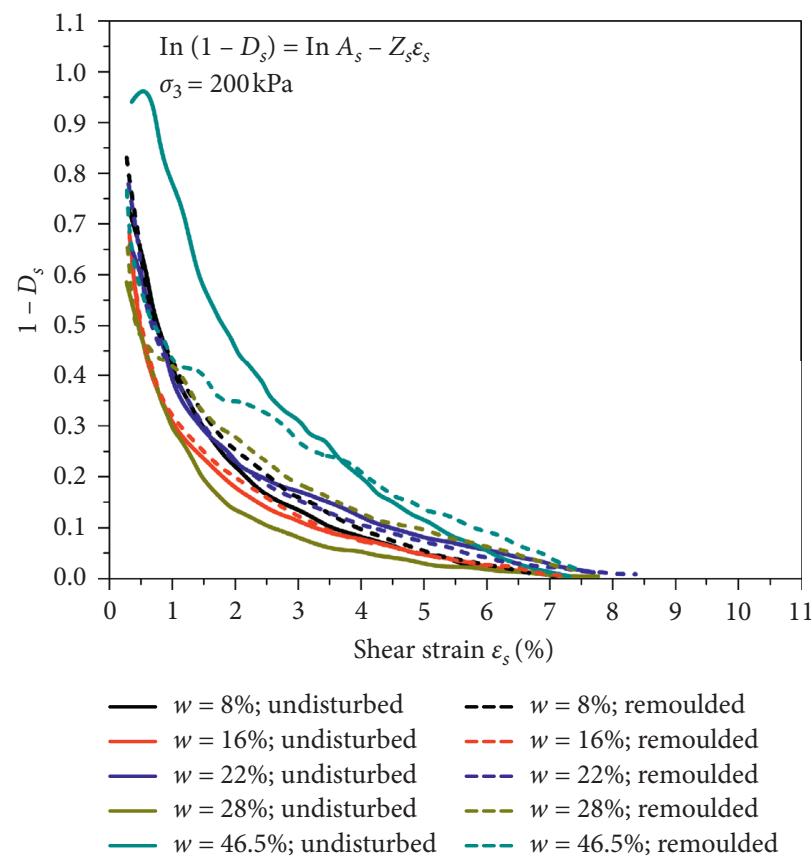

(c)

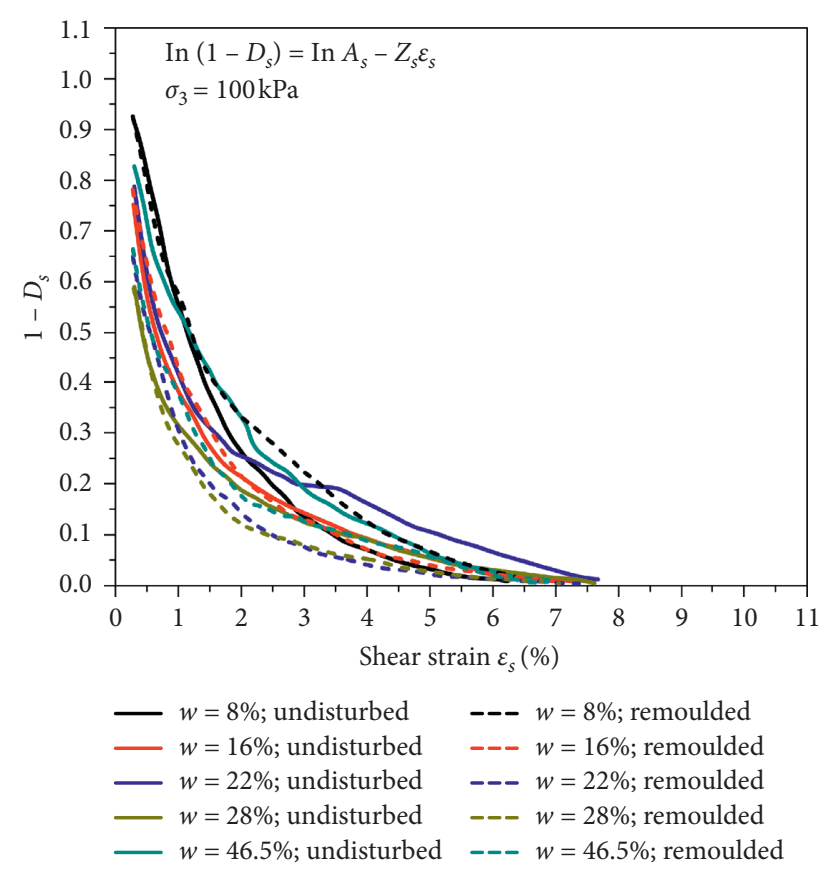

(b)

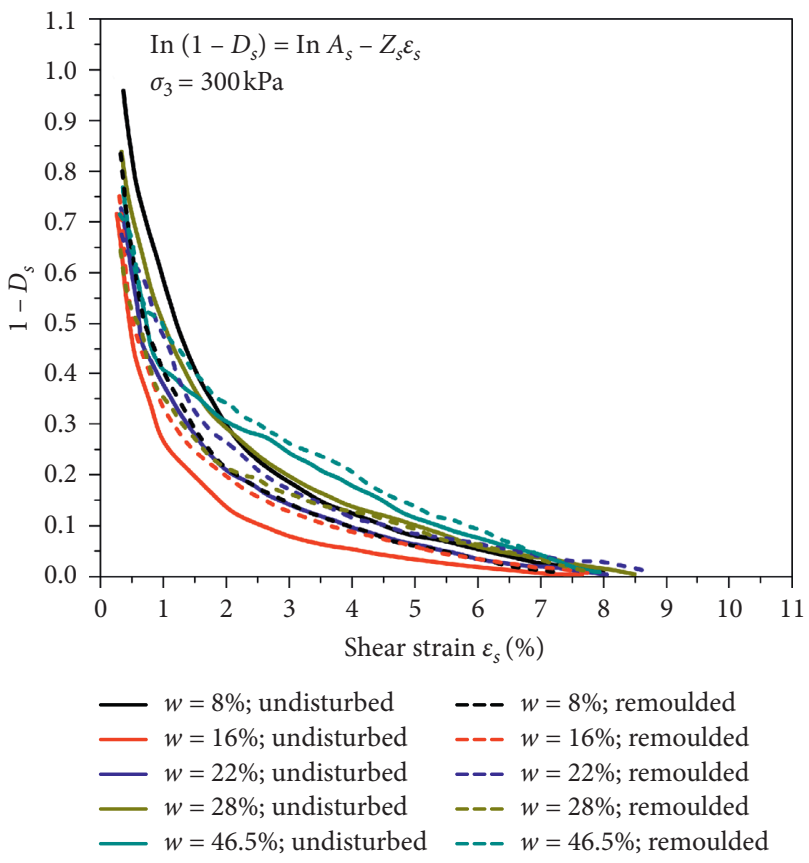

(d)

Figure 7: Evolution curves of disturbance functions based on shear strain for undisturbed and remoulded soil samples. (a) $\sigma_{3}=50 \mathrm{kPa}$; (b) $\sigma_{3}=100 \mathrm{kPa}$; (c) $\sigma_{3}=200 \mathrm{kPa}$; (d) $\sigma_{3}=300 \mathrm{kPa}$.

the effect of moisture content on the structural behavior of loess soil becomes severer, demonstrating that a higher confining pressure (e.g., $400 \mathrm{kPa}$ ) has an adverse effect on the structural behavior of loess soil. Nevertheless, the validation of the proposed disturbance functions has demonstrated the applicability of the proposed disturbance function to the loess soil in other areas.

\section{Conclusions}

To investigate the disturbance evolution behavior of loess soil, consolidated and drained triaxial compression tests were performed on undisturbed and remoulded Xi'an loess soil samples prepared at five different moisture contents and tested at four different confining pressures. The single- 


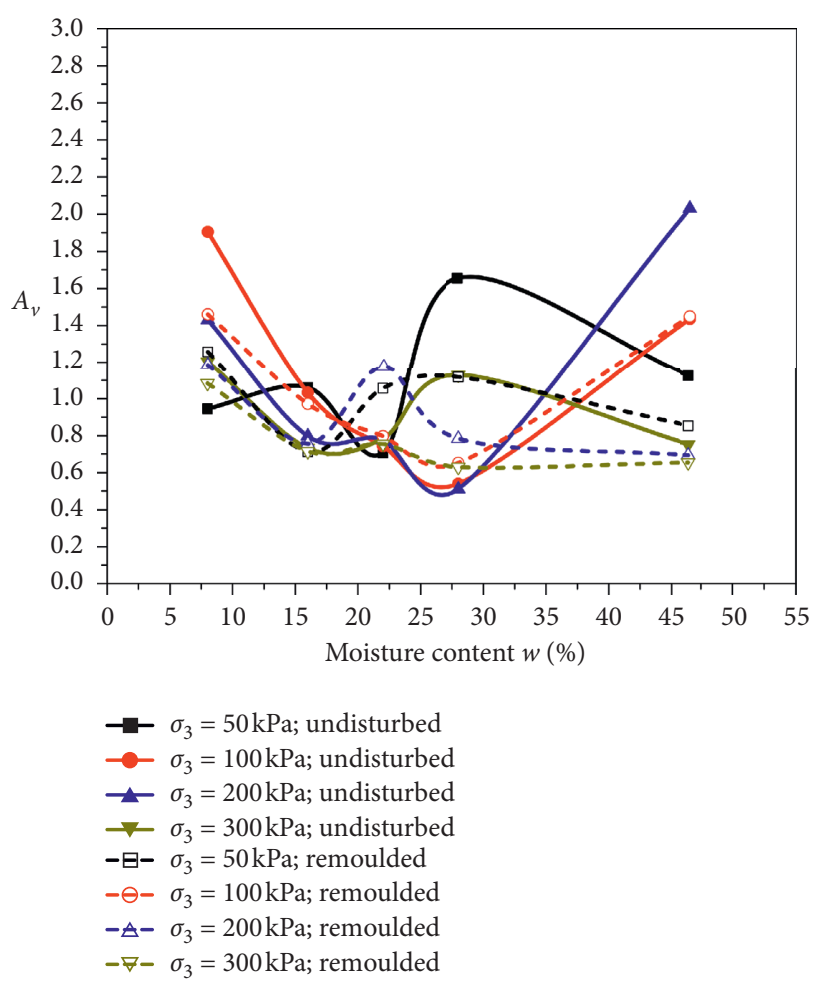

(a)

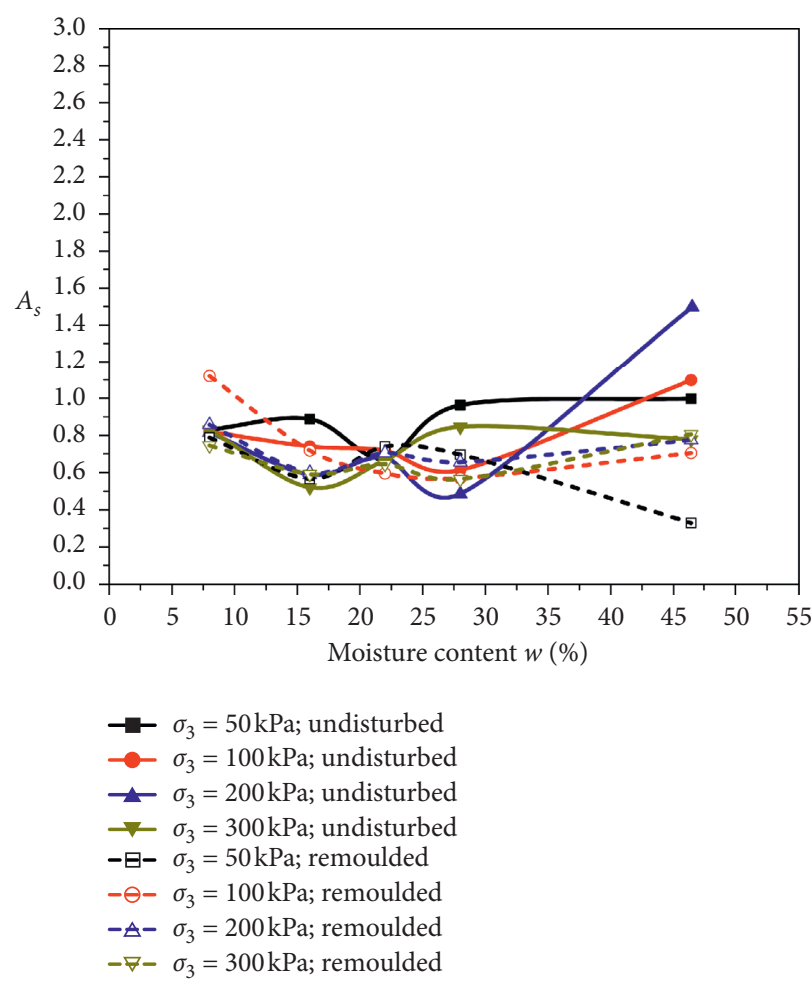

(c)

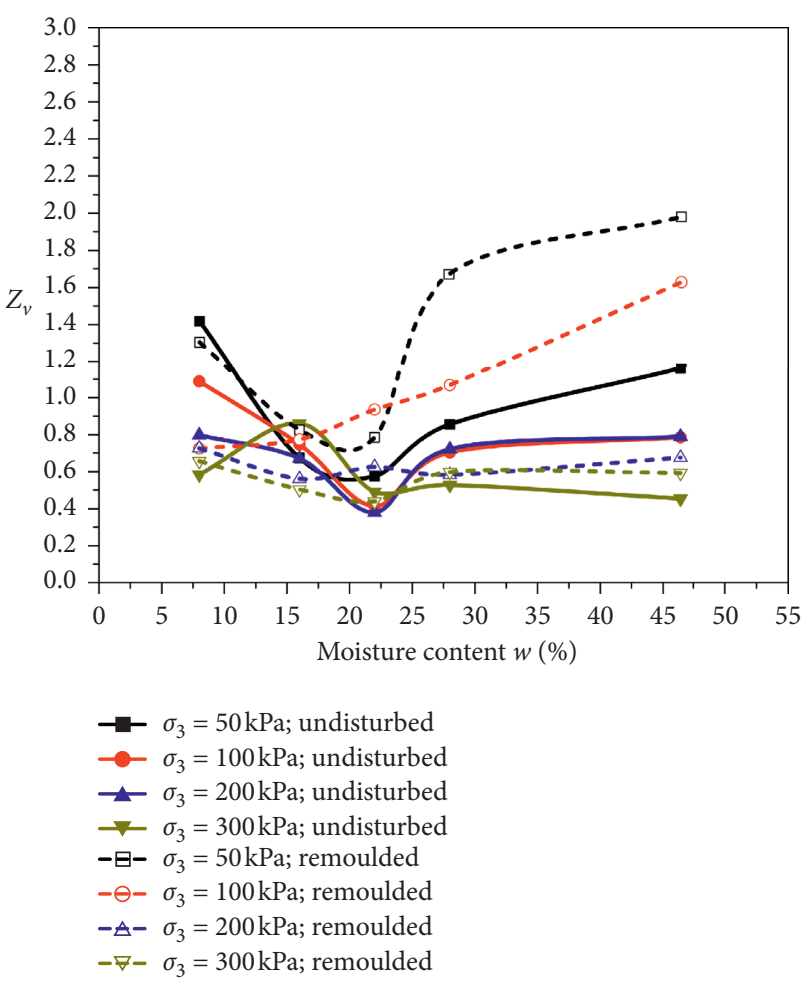

(b)

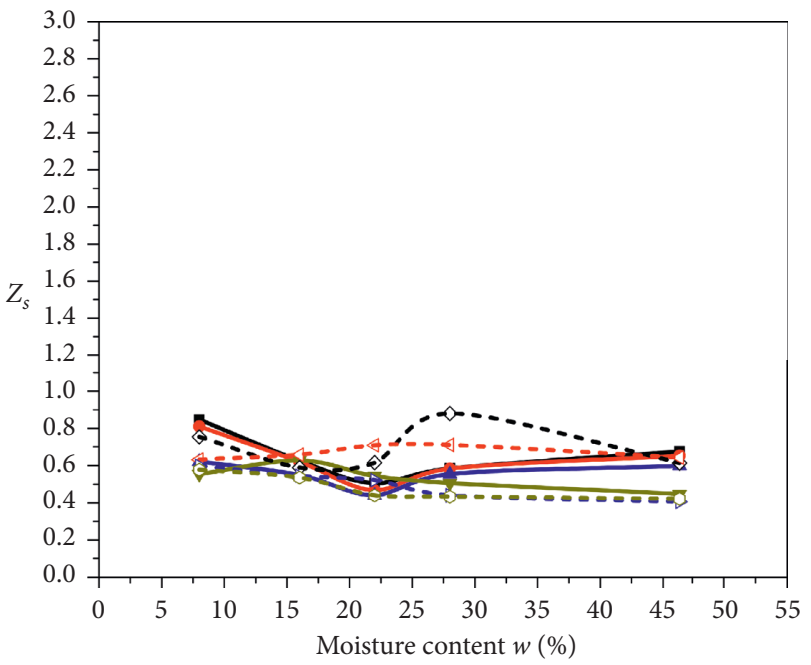

$\rightarrow-\sigma_{3}=50 \mathrm{kPa}$; undisturbed
$-\sigma_{3}=100 \mathrm{kPa}$; undisturbed
$-\sigma_{3}=200 \mathrm{kPa}$; undisturbed
$\neg-\sigma_{3}=300 \mathrm{kPa}$; undisturbed
$-\boxminus-\sigma_{3}=50 \mathrm{kPa}$ remoulded
$-\ominus-\sigma_{3}=100 \mathrm{kPa}$; remoulded
$-\triangle-\sigma_{3}=200 \mathrm{kPa}$ remoulded
$-\nabla-\sigma_{3}=300 \mathrm{kPa}$; remoulded

(d)

FIGURE 8: Effects of confining pressure and moisture content on parameters of double-parameter disturbance function for undisturbed and remoulded soil samples (a) $A_{v}$; (b) $Z_{v}$; (c) $A_{s}$; (d) $Z_{s}$.

parameter disturbance function $D_{1}$ with the deformation modulus as its parameter and the double-parameter disturbance function $D_{2}$ with the shear modulus and the bulk modulus as its parameters were proposed. Based on the analysis of the testing results and the proposed disturbance functions, the following conclusions can be drawn: 


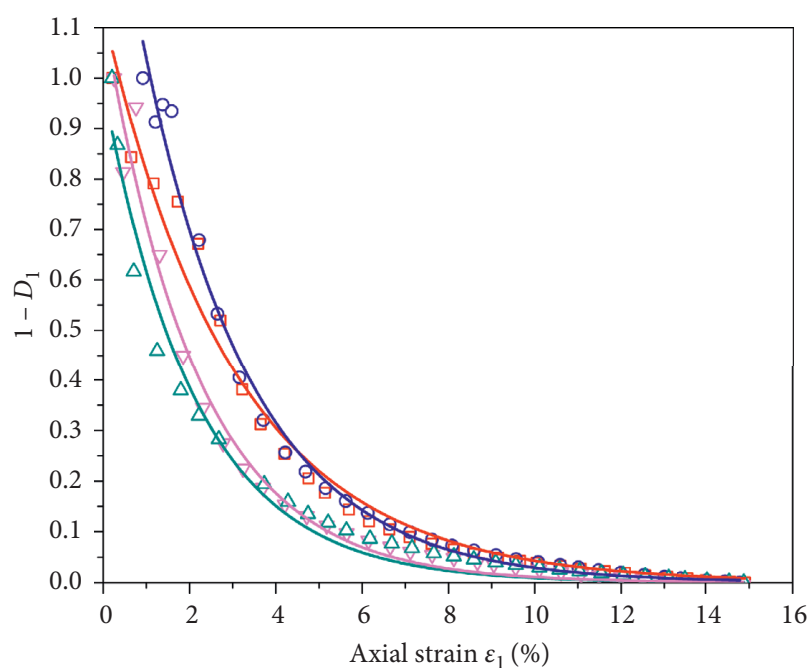

Experimental results by Chu and Shao (2018) [24]
$\square \quad w=10 \%$
$\triangle w=20 \%$
○ $w=15 \%$
$\nabla w=25 \%$

Predicted results by the single-parameter disturbance function proposed in this study
$w=10 \%$
- $w=20 \%$
- $w=15 \%$
$-w=25 \%$

(a)

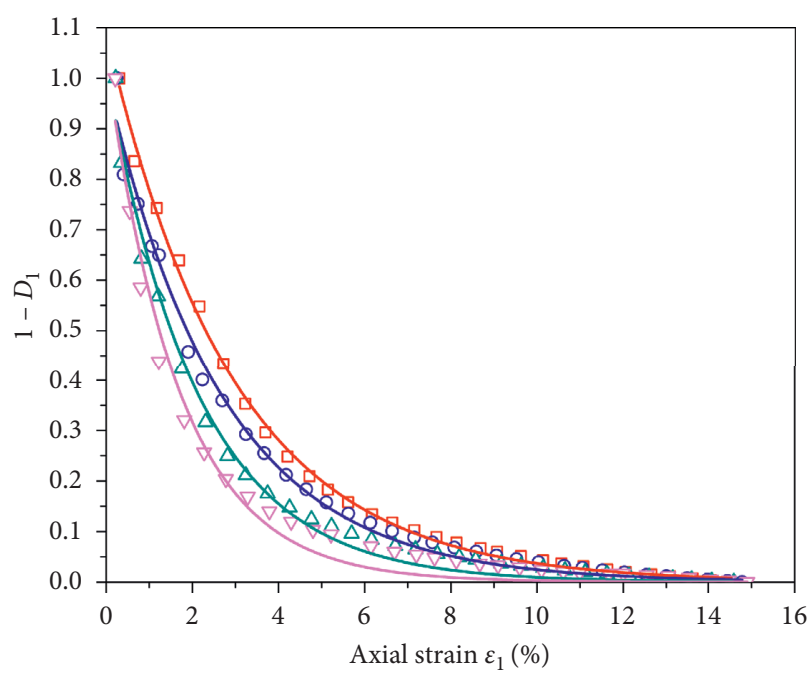

Experimental results by Chu and Shao (2018) [24]

$$
\begin{array}{ll}
\square w=10 \% & \triangle w=20 \% \\
\bigcirc w=15 \% & \nabla w=25 \%
\end{array}
$$

Predicted results by the single-parameter disturbance function proposed in this study

$$
\begin{aligned}
& \text { - } w=10 \% \\
& -w=15 \% \\
& \begin{aligned}
w & =20 \% \\
w & =25 \%
\end{aligned}
\end{aligned}
$$

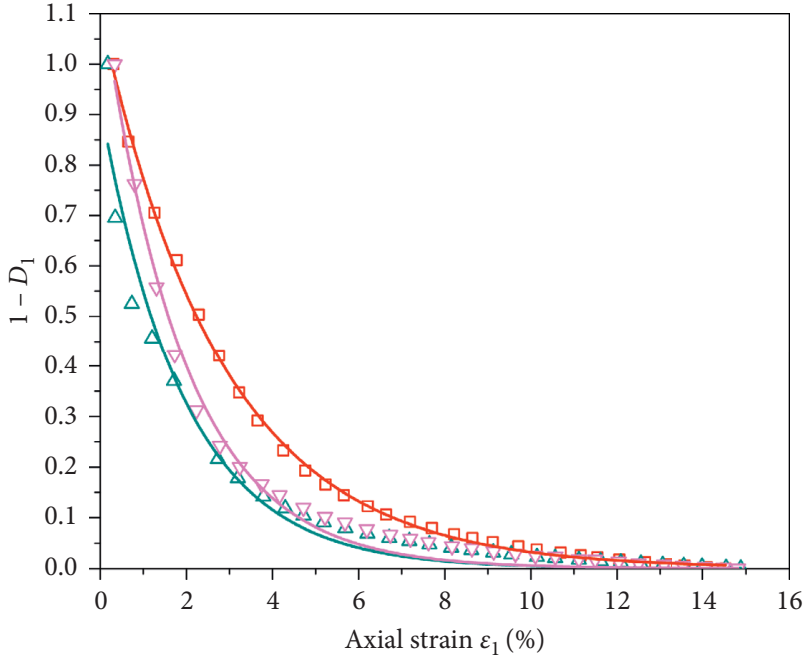

Experimental results by Chu and Shao (2018) [24]

$$
\begin{aligned}
& \square \quad w=10 \% \\
& \Delta \quad w=20 \% \\
& \nabla \quad w=25 \%
\end{aligned}
$$

Predicted results by the single-parameter disturbance function proposed in this study

$w=10 \%$

$-w=20 \%$

$w=25 \%$

(b)

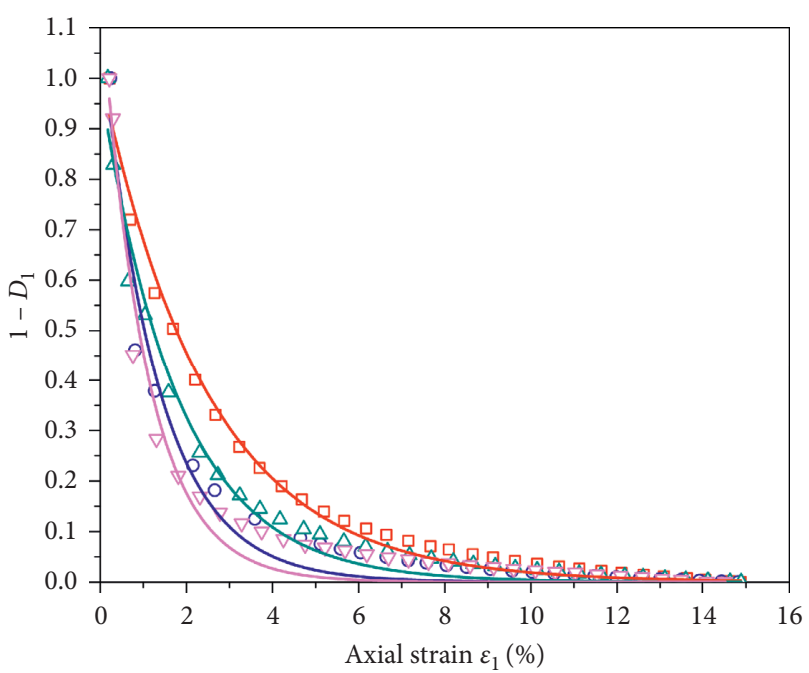

Experimental results by Chu and Shao (2018) [24]
$\square w=10 \%$
$\triangle \quad w=20 \%$
○ $w=15 \%$
$\nabla w=25 \%$

Predicted results by the single-parameter disturbance function proposed in this study

- $w=10 \%$

$w=20 \%$

$w=15 \%$

(d)

Figure 9: Validation of the single-parameter disturbance function against the experimental results by Chu and Shao [24] at different moisture contents and confining pressures. (a) $\sigma_{3}=100 \mathrm{kPa}$; (b) $\sigma_{3}=200 \mathrm{kPa}$; (c) $\sigma_{3}=300 \mathrm{kPa}$; (d) $\sigma_{3}=400 \mathrm{kPa}$.

(1) The single-parameter disturbance function, fitted as an exponential function with the secant modulus as its parameter, is capable of quantifying the strength of the structural disturbance. The performance of the single-parameter disturbance function in describing undisturbed loess soil is remarkable. 


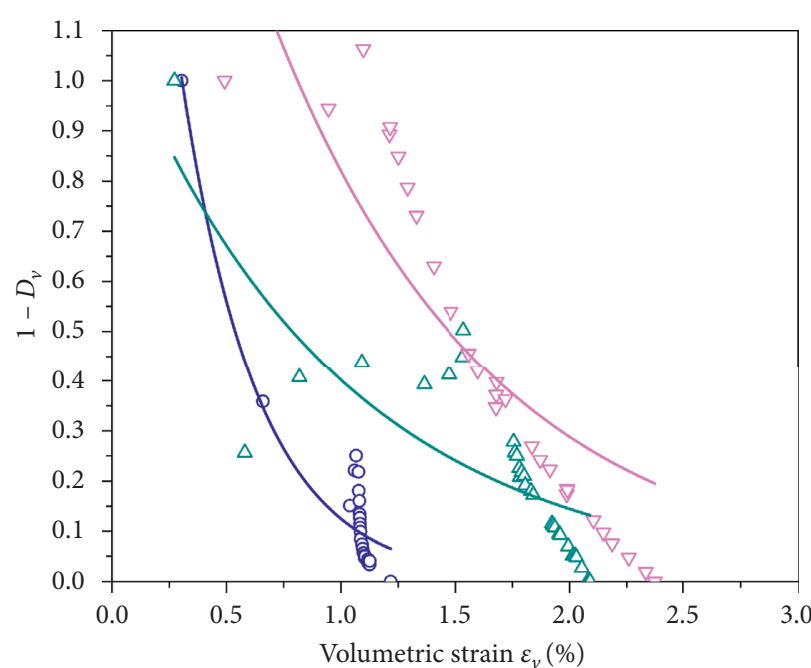

Experimental results by Chu and Shao (2018) [24]

$$
\begin{aligned}
& \triangle \quad w=15 \% \\
& \triangle \quad w=20 \% \\
& \nabla \quad w=25 \%
\end{aligned}
$$

Predicted results by the double-parameter disturbance function based on the bulk modulus proposed in this study

$$
\begin{aligned}
w & =15 \% \\
w & =20 \% \\
w & =25 \%
\end{aligned}
$$

(a)

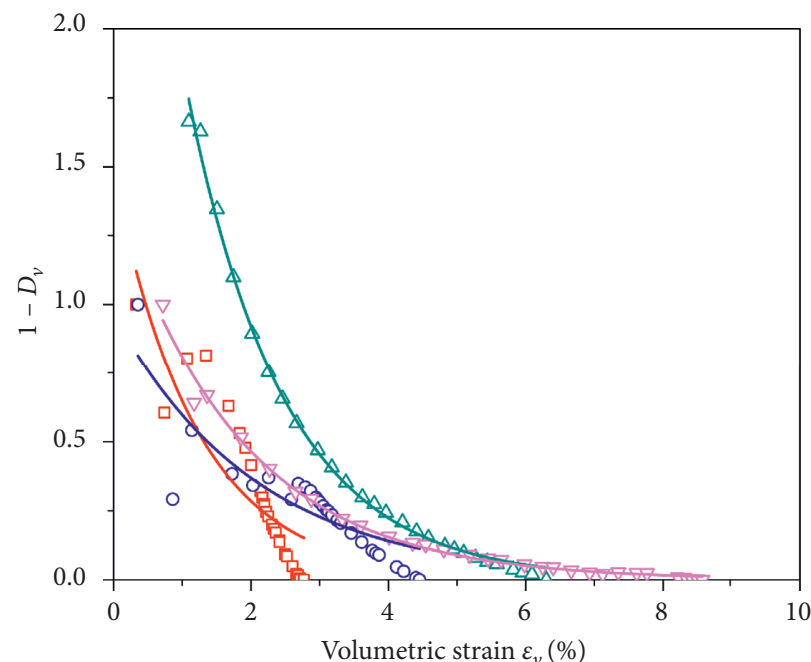

Experimental results by Chu and Shao (2018) [24]

$$
\begin{array}{ll}
\square w=10 \% & \triangle w=20 \% \\
\bigcirc w=15 \% & \nabla w=25 \%
\end{array}
$$

Predicted results by the double-parameter disturbance function based on the bulk modulus proposed in this study

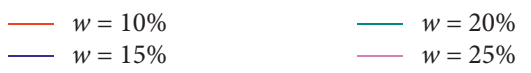

(c)

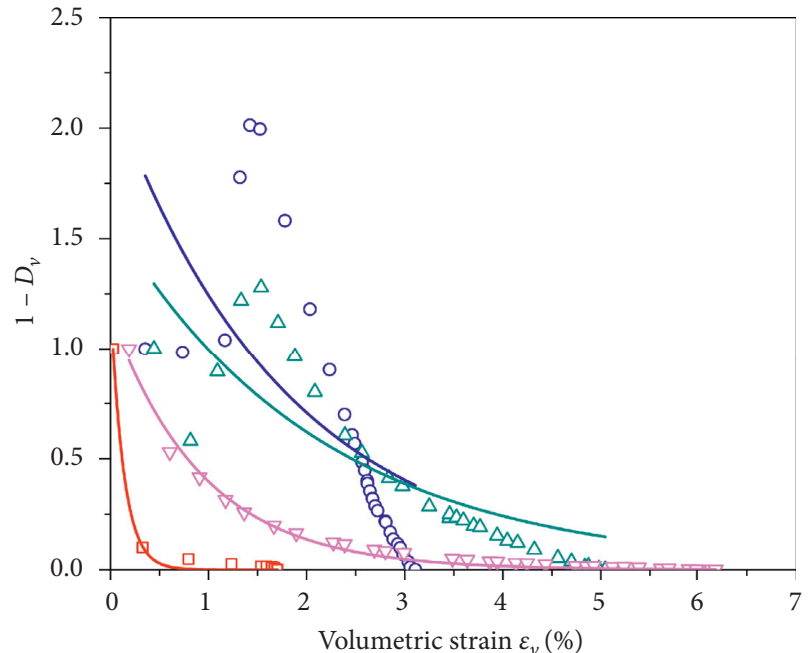

Experimental results by Chu and Shao (2018) [24]

$$
\begin{array}{ll}
\square w=10 \% & \triangle w=20 \% \\
\bigcirc w=15 \% & \nabla w=25 \%
\end{array}
$$

Predicted results by the double-parameter disturbance function based on the bulk modulus proposed in this study

$$
\text { - } w=10 \% \quad-w=20 \%
$$$$
-w=15 \% \quad w=25 \%
$$

(b)

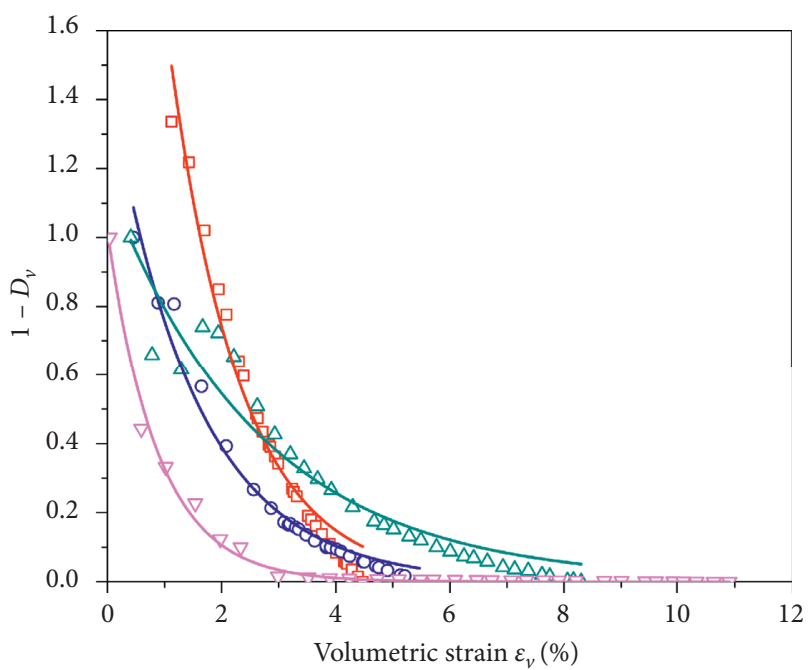

Experimental results by Chu and Shao (2018) [24]

$$
\begin{array}{ll}
\square w=10 \% & \triangle w=20 \% \\
\bigcirc w=15 \% & \nabla w=25 \%
\end{array}
$$

Predicted results by the double-parameter disturbance function based on the bulk modulus proposed in this study

$$
\begin{aligned}
& \text { - } w=10 \% \\
& \text { - } w=20 \% \\
& \text { - } w=25 \%
\end{aligned}
$$

(d)

FIGURE 10: Validation of the double-parameter disturbance function based on volumetric strain against the experimental results by Chu and Shao [24] at different moisture contents and confining pressures. (a) $\sigma_{3}=100 \mathrm{kPa}$; (b) $\sigma_{3}=200 \mathrm{kPa}$; (c) $\sigma_{3}=300 \mathrm{kPa}$; (d) $\sigma_{3}=400 \mathrm{kPa}$.

(2) The confining pressure and the moisture content have a great influence on the parameter $A$ of the disturbance function and have a slight influence on the parameter $Z$ of the disturbance function. The confining pressure and the moisture content have a great influence on the parameters of the disturbance 


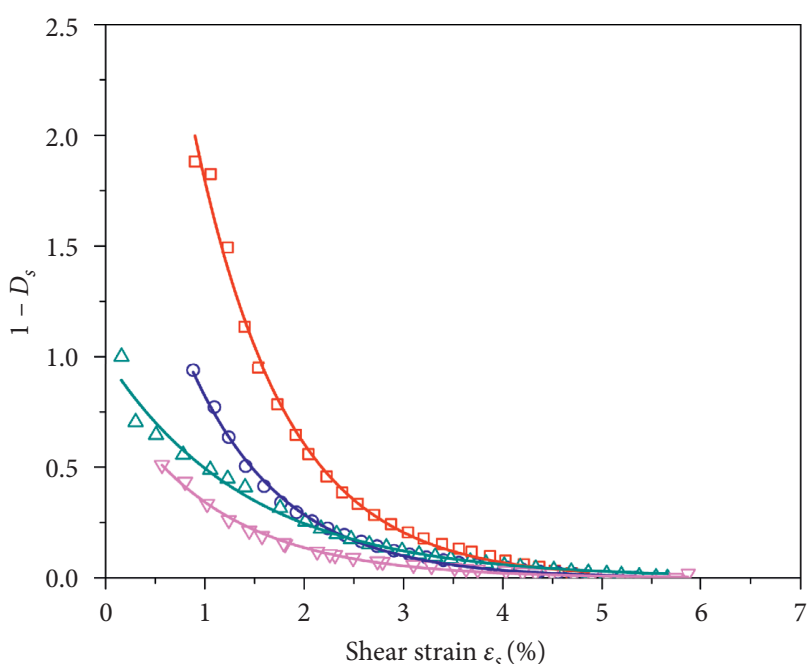

Experimental results by Chu and Shao (2018) [24]

$$
\begin{array}{ll}
\square w=10 \% & \triangle w=20 \% \\
\bigcirc w=15 \% & \nabla w=25 \%
\end{array}
$$

Predicted results by the double-parameter disturbance function based on the shear modulus proposed in this study

$$
w=10 \%
$$$$
\text { - } w=15 \%
$$$$
\text { - } w=20 \%
$$

(a)

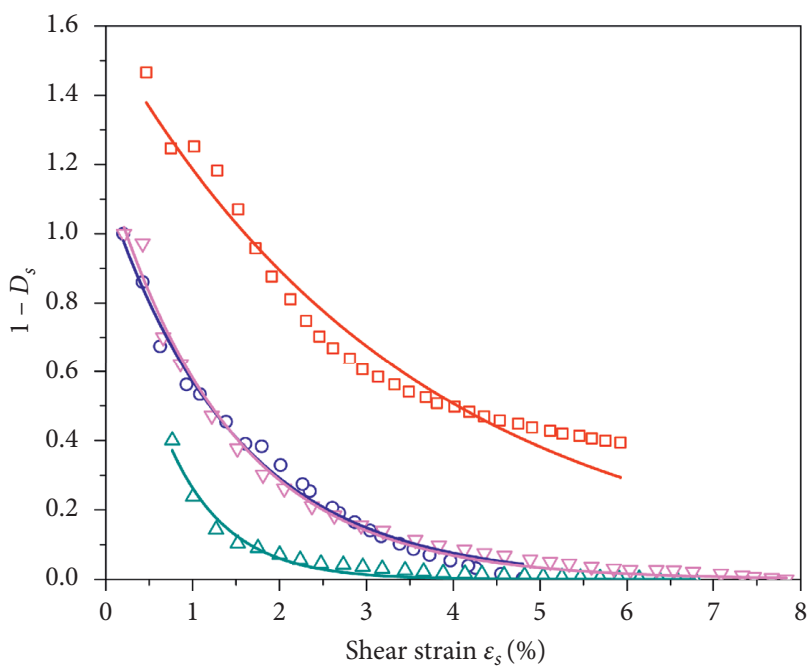

Experimental results by Chu and Shao (2018) [24]

$$
\begin{array}{ll}
\square w=10 \% & \triangle w=20 \% \\
\bigcirc w=15 \% & \nabla w=25 \%
\end{array}
$$

Predicted results by the double-parameter disturbance function based on the shear modulus proposed in this study

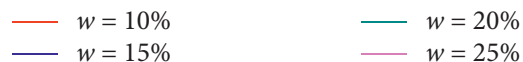

(c)

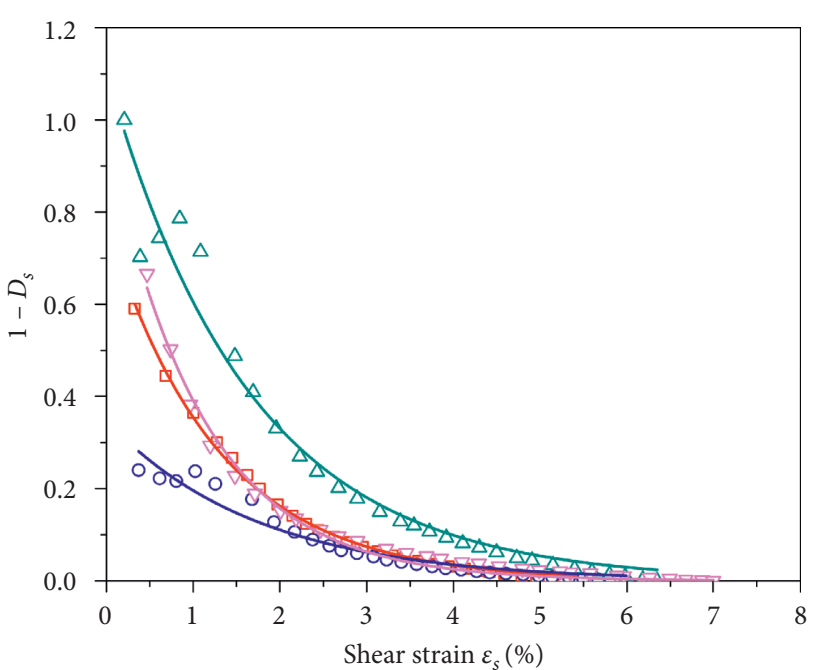

Experimental results by Chu and Shao (2018) [24]
$\square \quad w=10 \%$
$\triangle w=20 \%$
○ $w=15 \%$
$\nabla \quad w=25 \%$

Predicted results by the double-parameter disturbance function based on the shear modulus proposed in this study
$w=10 \%$
$w=20 \%$

$-w=15 \%$

$w=25 \%$

(b)

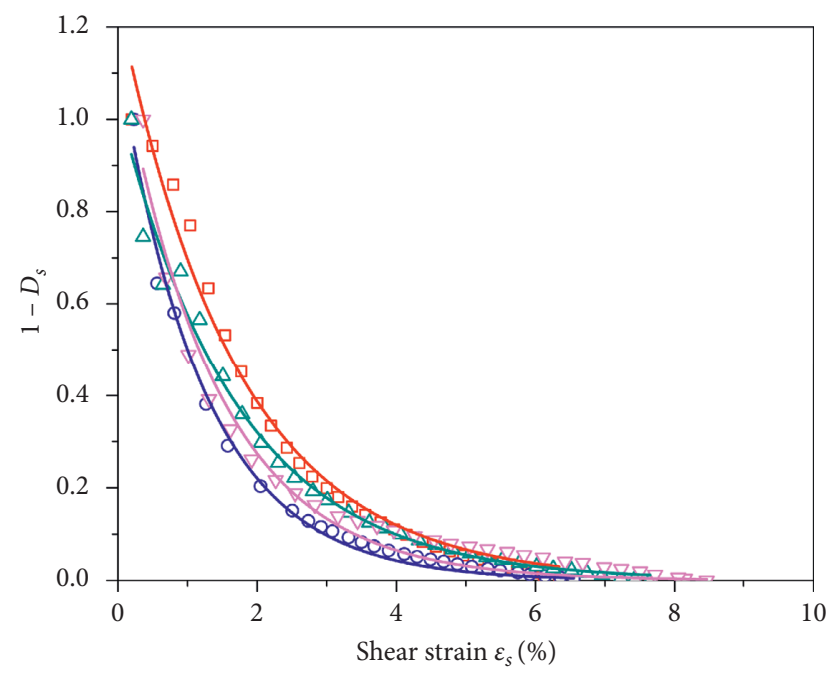

Experimental results by Chu and Shao (2018) [24]
$w=10 \%$
$\triangle \quad w=20 \%$
○ $w=15 \%$
$\nabla w=25 \%$

Predicted results by the double-parameter disturbance function based on the shear modulus proposed in this study
- $w=10 \%$
$w=20 \%$
$-w=15 \%$

(d)

Figure 11: Validation of the double-parameter disturbance function based on shear strain against the experimental results by Chu and Shao [24] at different moisture contents and confining pressures. (a) $\sigma_{3}=100 \mathrm{kPa}$; (b) $\sigma_{3}=200 \mathrm{kPa}$; (c) $\sigma_{3}=300 \mathrm{kPa}$; (d) $\sigma_{3}=400 \mathrm{kPa}$.

function for undisturbed soil samples and have a slight influence on the parameters of the disturbance function for remoulded soil samples.
(3) The double-parameter disturbance function with the shear modulus and the bulk modulus as its parameters takes account of the effects of deviatoric 
stress and spherical stress on strain. The evolution laws of the double-parameter disturbance functions based on shear strain and bulk strain can be conveniently and accurately described in exponential forms.

(4) The effects of moisture content and confining pressure on the parameters of the double-parameter disturbance function have no a steady rhythm. Additional tests are needed for further investigation into this phenomenon.

\section{Data Availability}

The data used to support the findings of this study are available from the corresponding author upon request.

\section{Conflicts of Interest}

The authors declare that there are no conflicts of interest.

\section{Acknowledgments}

This work was supported by the Natural Science Fund of the University in Anhui Province (nos. KJ2019ZD60 and KJ2013B223), the Excellent Young Talents Foundation Project in Anhui Province (no. 2012SQRL195), the Talent Introduction in Hefei University (no. 13RC10), the Provincial Quality Engineering Projects of the Education Department of Anhui Province (no. 2017zhkt383), and the Undergraduate Education Quality Project in Hefei University (no. 2018HFMOOC04 and 2018HFJC05).

\section{References}

[1] Z. Hu, K. Du, J. Lai, and Y. Xie, "Statistical analysis of influence of cover depth on loess tunnel deformation in NW China," Advances in Civil Engineering, vol. 2019, Article ID 2706976, 12 pages, 2019.

[2] Y. Li, S. Xu, H. Liu, E. Ma, and L. Wang, "Displacement and stress characteristics of tunnel foundation in collapsible loess ground reinforced by jet grouting columns," Advances in Civil Engineering, vol. 2018, Article ID 2352174, 16 pages, 2018.

[3] X. Zhang, Y. Lu, X. Li, Y. Lu, J. Sun, and W. Pan, "Multilevel collapsibility of loess under irrigation in Jinya Town, Gansu Province, China," Advances in Civil Engineering, vol. 2019, Article ID 2153679, 13 pages, 2019.

[4] Z. Zhou and Y. Xie, "Experiment on improving bearing capacity of pile foundation in loess area by postgrouting," Advances in Civil Engineering, vol. 2019, Article ID 9250472, 11 pages, 2019.

[5] Z. Zhou, T. Yang, and H. Fan, "A full-scale field study on bearing characteristics of cast-in-place piles with different hole-forming methods in Loess area," Advances in Civil Engineering, vol. 2019, Article ID 1450163, 12 pages, 2019.

[6] G. Gao, "Classification of microstructure and collapsibility of loess," Chinese Science, vol. 12, pp. 1203-1208, 1980.

[7] Z. Chen, "Discussion on effective stress of unsaturated soil," Journal of Geotechnical Engineering, vol. 16, no. 3, pp. 62-69, 1994.

[8] X. Fang, Y. Li, C. Shen, and Z. Chen, "Constitutive model of unsaturated undisturbed Q2 loess based on disturbed state concept," Journal of Logistical Engineering University, vol. 33, no. 4, pp. 1-8, 2017.

[9] Z. Shen, "Masonry model of structural clay," Geotechnical Mechanics, vol. 21, no. 1, pp. 1-4, 2000.

[10] Z. Shen, "Elastoplastic damage model of structural clay," Journal of Geotechnical Engineering, vol. 15, no. 3, pp. 21-28, 1993.

[11] Z. Shen and Z. Hu, "Binary medium model of loess," Journal of Water Conservancy, vol. 7, pp. 1-6, 2003.

[12] D. Xie and J. Qi, "Soil structure characteristics and new approach in research on its quantitative parameter," Chinese Journal of Geotechnical Engineering, vol. 21, no. 6, pp. 651656, 1999.

[13] Y. Luo, D. Xie, S. Shao, and A. Zhang, "Structural parameter of soil under complex stress conditions," Chinese Journal of Rock Mechanics and Engineering, vol. 23, no. 24, pp. 42484251, 2004.

[14] S. Shao, W. Zheng, Z. Wang, and S. Wang, "Structural index of loess and its testing method," Rock and Soil Mechanics, vol. 31, no. 1, pp. 15-19, 2010.

[15] C. S. Desai, "A consistent finite element technique for work softening behavior," Proceedings of International Conference on Computer Methods in Nonlinear Mechanics, University of Texas, Austin, TX, USA, pp. 403-419, 1974.

[16] C. S. Desai, S. Somasundaram, and G. Frantziskonis, "A hierarchical approach for constitutive modelling of geologic materials," International Journal for Numerical and Analytical Methods in Geomechanics, vol. 3, no. 10, pp. 225-257, 1986.

[17] C. S. Desai and J. Toth, "Disturbed state constitutive modeling based on stress-strain and nondestructive behavior," International Journal of Solids and Structures, vol. 33, no. 11, pp. 1619-1650, 1996.

[18] C. S. Desai, "Constitutive modeling of materials and contacts using the disturbed state concept: part 1-background and analysis," Computers \& Structures, vol. 146, pp. 214-233, 2015.

[19] C. S. Desai, "Disturbed state concept as unified constitutive modeling approach," Journal of Rock Mechanics and Geotechnical Engineering, vol. 8, no. 3, pp. 277-293, 2016.

[20] Y. Xu, Research on the disturbed state constitutive model of the structural loess and application, Ph.D. thesis, Xi' an University of Architecture and Technology, Xi'an, China, 2011.

[21] Y. Xu, "Experimental study on one-dimensional disturbance evolution of Q3 loess," Journal of West Anhui University, vol. 34, no. 5, pp. 110-114, 2018.

[22] Y. Xu, "A 1D compression model for loess based on disturbed state concept," Revue des Composites et des Materiaux Avances, vol. 29, no. 2, pp. 125-129, 2019.

[23] S. Shao and F. Chu, "Experimental study on constitutive model of structural Q3 loess based on disturbed state concept," Journal of Rock Mechanics and Engineering, vol. 35, no. 7, pp. 1494-1500, 2016.

[24] F. Chu and S. Shao, "Experimental study on constitutive model of $\mathrm{Q}_{3}$ structural loess in Longdong based on disturbed state concept," Journal of Rock Mechanics and Engineering, vol. 37, no. 9, pp. 2180-2188, 2018.

[25] C. Yang, J. P. Carter, and D. Sheng, "Description of compression behaviour of structured soils and its application," Canadian Geotechnical Journal, vol. 51, no. 8, pp. 921-933, 2015.

[26] C. Yang, X. Liu, X. Liu, C. Yang, and J. P. Carter, "Constitutive modelling of Otaniemi soft clay in both natural and reconstituted states," Computers and Geotechnics, vol. 70, pp. 8395, 2015. 
[27] Y. Xiao, Y. Sun, F. Yin, H. Liu, and J. Xiang, "Constitutive modeling for transparent granular soils," International Journal of Geomechanics, vol. 17, no. 7, Article ID 4016150, 2017.

[28] T.-L. Wang, H.-F. Song, Z.-R. Yue, T.-F. Hu, T.-C. Sun, and H.-B. Zhang, "Freeze-thaw durability of cement-stabilized macadam subgrade and its compaction quality index," Cold Regions Science and Technology, vol. 160, no. 4, pp. 13-20, 2019.

[29] X. Xu, Q. Li, and G. Xu, "Investigation on the behavior of frozen silty clay subjected to monotonic and cyclic triaxial loading," Acta Geotechnica, pp. 1-14, 2019, In Press.

[30] Z. Zhou, W. Ma, S. Zhang, H. Du, Y. Mu, and G. Li, "Multiaxial creep of frozen loess," Mechanics of Materials, vol. 95, pp. 172-191, 2016.

[31] X. Xu, W. Zhang, C. Fan, Y. Lai, and J. Wu, "Effect of freeze-thaw cycles on the accumulative deformation of frozen clay under cyclic loading conditions: experimental evidence and theoretical model," Road Materials and Pavement Design, pp. 1-17, 2019, In Press.

[32] Y. Wang, H. Zhang, H. Lin, Y. Zhao, and Y. Liu, "Fracture behaviour of central-flawed rock plate under uniaxial compression," Theoretical and Applied Fracture Mechanics, vol. 106, p. 102503, 2020.

[33] P. Guo, X. Gong, and Y. Wang, "Displacement and force analyses of braced structure of deep excavation considering unsymmetrical surcharge effect," Computers and Geotechnics, vol. 113, Article ID 103102, 2019.

[34] Z. Zhou, W. Ma, S. Zhang, Y. Mu, and G. Li, "Experimental investigation of the path-dependent strength and deformation behaviours of frozen loess," Engineering Geology, vol. 265, Article ID 105449, 2020.

[35] Z. Wu, S. Xu, D. Chen, D. Zhao, and D. Zhang, "An experimental study of the influence of structural parameters on dynamic characteristics of loess," "Soil Dynamics and Earthquake Engineering, vol. 132, Article ID 106067, 2020.

[36] W. Zhang, A. Guo, and C. Lin, "Effects of cyclic freeze and thaw on engineering properties of compacted loess and limestabilized loess," Journal of Materials in Civil Engineering, vol. 21, no. 9, Article ID 4019205, 2019.

[37] Z. Zhen, G. Ma, H. Zhang, Y. Gai, and Z. Su, "Thermal conductivities of remolded and undisturbed loess," Journal of Materials in Civil Engineering, vol. 31, no. 2, Article ID 4018379, 2019.

[38] D. Wang, Y. Du, and J. Xiao, "Shear properties of stabilized loess using novel reactive magnesia-bearing binders," Journal of Materials in Civil Engineering, vol. 31, no. 5, Article ID 4019039, 2019.

[39] X. Pei, F. Zhang, W. Wu, and S. Liang, "Physicochemical and index properties of loess stabilized with lime and fly ash piles," Applied Clay Science, vol. 114, pp. 77-84, 2015.

[40] A. Tabarsa, N. Latifi, C. L. Meehan, and K. N. Manahiloh, "Laboratory investigation and field evaluation of loess improvement using nanoclay-a sustainable material for construction," Construction and Building Materials, vol. 158, pp. 454-463, 2018. 